\title{
Mathematical expression of discharge capacity of compound open channels using MARS technique
}

\author{
Abbas Parsaie* and Amir Hamzeh Haghiabi \\ Water Engineering Department, Lorestan University, Khorramabad, Iran. \\ ${ }^{*}$ Corresponding author. e-mail: Abbas_Parsaie@yahoo.com
}

In this paper, analytical methods, artificial neural network (ANN) and multivariate adaptive regression splines (MARS) techniques were utilised to estimate the discharge capacity of compound open channels (COC). To this end, related datasets were collected from literature. The results showed that the divided channel method with a coefficient of determination $\left(R^{2}\right)$ value of 0.76 and root mean square error (RMSE) value of 0.162 has the best performance, among the various analytical methods tested. The performance of applied soft computing models with $R^{2}=0.97$ and $\mathrm{RMSE}=0.03$ was found to be more accurate than analytical approaches. Comparison of MARS with the ANN model, in terms of developed discrepancy ratio (DDR) index, showed that the accuracy of MARS model was better than that of MLP model. Reviewing the structure of the derived MARS model showed that the longitudinal slope of the channel $(S)$, relative flow depth $\left(H_{r}\right)$ and relative area $\left(A_{r}\right)$ have a high impact on modelling and forecasting the discharge capacity of COCs.

\section{Introduction}

Discharge of flow in natural streams is a basic parameter for developing water engineering projects including dam construction, water harvesting, river intakes, etc. (Dehdar-behbahani and Parsaie 2016). Government bodies, therefore, construct hydrometric stations to directly measure discharge of the flow along important rivers (Lenton and Muller 2012). Another method of estimation of flow discharge is using indirect approaches that apply mathematical operations. Indirect approaches can be divided into analytical methods and modern computations. Calculation of discharge of flow in rivers using analytical approaches is based on classical empirical formulas such as Manning and Chezy formulas. The use of these formulas lead to obvious errors in the river-engineering projects (Myers 1987; Chatila and Townsend 1996; Reddy et al. 2014; Fernandes et al. 2015; Parsaie 2016;
Parsaie et al. 2016b). Researchers have, therefore, attempted to modify and improve accuracy of these formulas in order to use them in river-engineering projects. One powerful approach that has been recently proposed and widely used in river-engineering problems is the compound open channel (COC) idea (Chow 2009; Chow et al. 2013). Classical formulas consider the cross-section of flow as en-bloc and one value is considered for roughness coefficients across all parts of the cross-section; whereas in the COC idea, the flow cross-section is separated into main channel and floodplains (Naot et al. 1993; Chaudhry 2007). The main advantage of COC compared to classical ones is related to this point. Figure 1 shows the sketch of a COC.

In this figure, $n_{m c}$ and $n_{f p}$ define the roughness coefficients of main channel and floodplains, respectively. $H$ introduces the depth of flow in the main channel, and $h$ is the main channel depth. Using the COC idea, researchers have proposed several

Keywords. Flow discharge; compound open channel; soft computing; river engineering. 


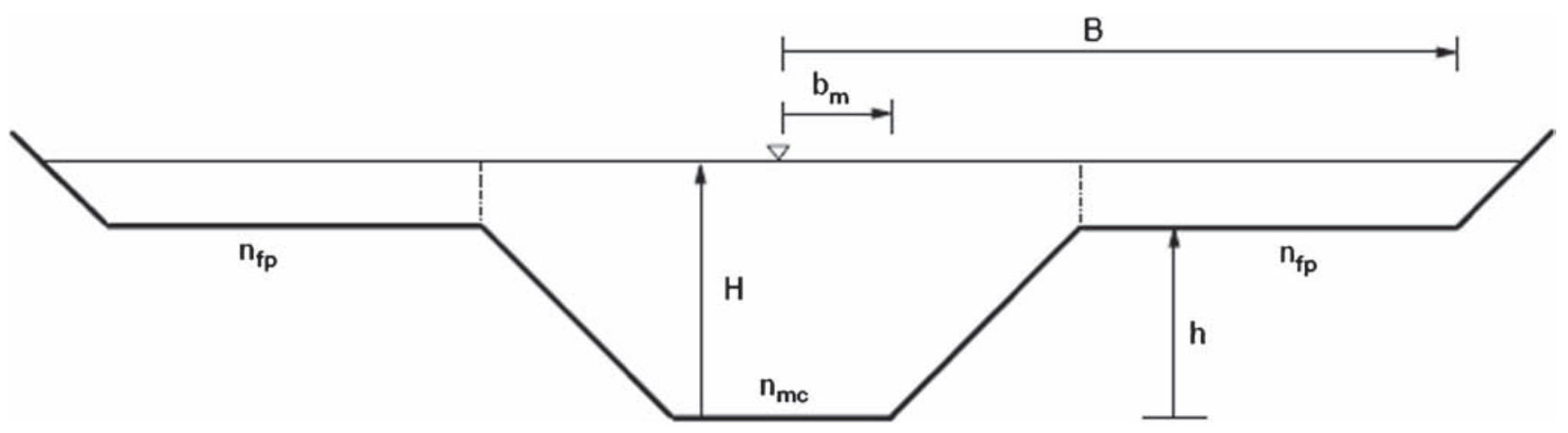

Figure 1. A schematic of a compound open channel cross-section.

analytical approaches to estimate discharge capacity of natural streams (Subramanya 2009; Mohanty and Khatua 2014) such as the single channel method (SCM), the divided channel method (DCM), and the coherence method $(\mathrm{COH})$. Researchers have attempted to utilise these methods to estimate flow discharge and they have also evaluated the performance of each one in laboratory and field studies (Sahu 2012). In this regard, Seckin (2004) applied SCM, COH and DCM methods to evaluate the discharge capacity of COCs. Results of his study showed that the $\mathrm{COH}$ method was more accurate when compared to DCM and SCM. Seckin et al. (2009) applied 2D formulas for forecasting discharge capacity of COCs. To this purpose, they assessed and compared 2D formulas and the traditional 1D formulas including SCM and DCM. The results of these studies showed that $2 \mathrm{D}$ formulas had better performance compared to traditional formulas. Khatua et al. (2012) proposed a modified divided channel method (MDCM) to estimate the discharge capacity of COC. They stated that results of their proposed method could be utilised for practical problems. Recently, by developing the soft computing techniques in water resource research, such as in assessment of water quality (Noori et al. 2012, 2015, 2016), river pollution modelling (Najafzadeh and Lim 2015; Parsaie and Haghiabi 2015; Azamathulla et al. 2016; Najafzadeh and Tafarojnoruz 2016), scouring downstream of hydraulic structures (Najafzadeh et al. 2013, 2016; Noori and Hooshyaripor 2014; Najafzadeh 2016), investigators have applied them to accurately estimate the discharge capacity of rivers based COC concept. In this regard, using artificial neural network (ANN), group method of data handling (GMDH) (Najafzadeh and Zahiri 2015), support vector machine (SVM), genetic expression method (GEM), and M5 model trees (Unal et al. 2010; Sahu et al. 2011; Azamathulla and Zahiri 2012; Zahiri and Azamathulla 2014) have been employed. Literature review shows that there is no report of evaluation of the performance of multivariate adaptive regression splines (MARS) models for estimating the discharge of flow in natural streams, based on concept of COC. Therefore, in this study, MARS has been utilised to estimate discharge capacity of COCs. In the following sections of this article, a comparison is made between the results of MARS, analytical approaches and multilayer perceptron (MLP) neural network.

MARS model was introduced by Friedman (1991) and was proposed as a novel approach for modelling the hydrology phenomena. This model has high ability for mapping the relation between the independent and dependent variables in any complex system which is based on dataset. This technique has been successfully used in some areas of hydrology engineering such as estimation of the scour depth, downstream of hydraulic structures, river mixing, river discharge forecasting, rainfallrunoff modelling, etc. (Sharda et al. 2008; Zhang and Goh 2014; Samadi et al. 2015; Haghiabi 2016a, b; Parsaie et al. 2016a). MARS technique is categorised as a smart function fitting methods. This means that MARS technique can define the most effective parameters in mathematical expressions of relation between input(s) and output(s), in complex systems. This point of the MARS model leads to assign more weights to most importance parameters that consequently lead to obtain derived model that is more reliable.

\section{Materials and method}

Discharge capacity of COCs is proportional to hydraulic and geometric characteristics. Parameters affecting flow discharge are given in equation (1).

$$
Q=f\left(f_{f p}, f_{m c}, A_{f p}, A_{m c}, R_{f p}, R_{m c}, S, h, H-h\right),
$$

where $f_{f p}$ and $f_{m c}$ are the roughnesses of main channel and floodplains; $A_{f p}$ and $A_{m c}$ are the areas of the main channel and floodplains; $R_{f p}$ and $R_{m c}$ are the hydraulic radii of the main channel and floodplains and $S$ is the longitudinal slope of COC. Sahu et al. (2011) arranged these variables as 
dimensionless parameters (equation 2) to estimate the discharge capacity of COCs and used them as input variables for developing a neural network model. Most of the analytical approaches and some soft computing research are based on dimension parameters.

$$
Q=\psi\left(f_{r}, A_{r}, R_{r}, S, H_{r}\right),
$$

where $f_{r}$ is the relative roughness and is defined as $f_{m c} / f_{f p} ; A_{r}$ is the relative area and is defined as $A_{m c} /$ $A_{f p}, R_{r}$ is the hydraulic radius and is defined as $R_{m c} / R_{f p}$, and $H_{r}$ is the relative depth and defined as $(H-h) / H$. To evaluate the performance of the analytical approaches and develop ANN and MARS models, 396 datasets related to flow discharge presented in a peer-reviewed journal were collected. Table 1 presents the summary of collected dataset from references. The histograms of collected dataset are given in figure 2. Datasets were collected from published articles including Knight et al. (1984), Wormleaton and Hadjipanos (1985), Wormleaton and Merrett (1990) (UK Flood Channel Facility), Tang et al. (1999), Seckin (2004), Atabay and Knight (2006), Khatua et al. (2012), Lenton and Muller (2012), Mohanty and Khatua (2014).

Table 1. Summary of collected data related to discharge of flow in the compound channel.

\begin{tabular}{|c|c|c|c|c|c|c|c|c|c|c|}
\hline Author & Range & $H(\mathrm{~m})$ & $h(\mathrm{~m})$ & $\begin{array}{c}H-h \\
(\mathrm{~m})\end{array}$ & $B(\mathrm{~m})$ & $b(\mathrm{~m})$ & $n_{\mathrm{fp}}$ & $n_{\mathrm{mc}}$ & $S$ & $\begin{array}{c}Q \\
\left(\mathrm{~m}^{3} / \mathrm{s}\right)\end{array}$ \\
\hline \multirow[t]{4}{*}{ Knight and Demetriou (1984) } & Min & 0.085 & 0.08 & 0.009 & 0.15 & 0.08 & 0.0100 & 0.0100 & 0.0010 & 0.0049 \\
\hline & $\operatorname{Max}$ & 0.154 & 0.08 & 0.078 & 0.31 & 0.08 & 0.0100 & 0.0100 & 0.0010 & 0.0294 \\
\hline & AVG & 0.112 & 0.08 & 0.036 & 0.23 & 0.08 & 0.0100 & 0.0100 & 0.0010 & 0.0116 \\
\hline & STDEV & 0.022 & 0.00 & 0.022 & 0.06 & 0.00 & 0.0000 & 0.0000 & 0.0000 & 0.0068 \\
\hline \multirow[t]{4}{*}{ Wormleaton and Hadjipanos (1985) } & Min & 0.135 & 0.12 & 0.015 & 0.75 & 0.29 & 0.0110 & 0.0099 & 0.0004 & 0.0009 \\
\hline & $\operatorname{Max}$ & 0.210 & 0.12 & 0.090 & 0.75 & 0.29 & 0.0210 & 0.0099 & 0.0018 & 0.4800 \\
\hline & AVG & 0.167 & 0.12 & 0.047 & 0.75 & 0.29 & 0.0160 & 0.0099 & 0.0006 & 0.0372 \\
\hline & STDEV & 0.023 & 0.00 & 0.023 & 0.00 & 0.00 & 0.0042 & 0.0000 & 0.0003 & 0.0735 \\
\hline \multirow{4}{*}{$\begin{array}{l}\text { Wormleaton and Merrett (1990) } \\
\text { (FCF: UK Flood Channel Facility) }\end{array}$} & Min & 0.058 & 0.05 & 0.006 & 0.61 & 0.20 & 0.0091 & 0.0091 & 0.0001 & 0.0100 \\
\hline & Max & 0.302 & 0.15 & 0.152 & 5.00 & 0.75 & 0.0910 & 0.0210 & 0.0020 & 1.1142 \\
\hline & AVG & 0.169 & 0.12 & 0.050 & 2.40 & 0.58 & 0.0220 & 0.0113 & 0.0007 & 0.3230 \\
\hline & STDEV & 0.066 & 0.05 & 0.040 & 1.47 & 0.26 & 0.0239 & 0.0030 & 0.0009 & 0.2946 \\
\hline \multirow[t]{4}{*}{ Tang et al. (1999) } & Min & 0.056 & 0.05 & 0.006 & 0.61 & 0.20 & 0.0056 & 0.0079 & 0.0020 & 0.0130 \\
\hline & $\operatorname{Max}$ & 0.220 & 0.05 & 0.170 & 0.61 & 0.20 & 0.0957 & 0.0390 & 0.0020 & 0.2180 \\
\hline & AVG & 0.092 & 0.05 & 0.042 & 0.61 & 0.20 & 0.0346 & 0.0170 & 0.0020 & 0.0499 \\
\hline & STDEV & 0.042 & 0.00 & 0.042 & 0.00 & 0.00 & 0.0228 & 0.0093 & 0.0000 & 0.0546 \\
\hline \multirow[t]{4}{*}{ Seckin (2004) } & Min & 0.060 & 0.05 & 0.010 & 0.61 & 0.20 & 0.0090 & 0.0090 & 0.0020 & 0.0148 \\
\hline & $\operatorname{Max}$ & 0.168 & 0.05 & 0.118 & 0.61 & 0.20 & 0.0490 & 0.0090 & 0.0020 & 0.0553 \\
\hline & AVG & 0.090 & 0.05 & 0.040 & 0.61 & 0.20 & 0.0288 & 0.0090 & 0.0020 & 0.0299 \\
\hline & STDEV & 0.027 & 0.00 & 0.027 & 0.00 & 0.00 & 0.0177 & 0.0000 & 0.0000 & 0.0117 \\
\hline \multirow[t]{4}{*}{ Atabay and Knight (2006) } & Min & 0.061 & 0.05 & 0.011 & 0.61 & 0.20 & 0.0063 & 0.0091 & 0.0020 & 0.0180 \\
\hline & $\operatorname{Max}$ & 0.120 & 0.05 & 0.070 & 0.61 & 0.20 & 0.0112 & 0.0115 & 0.0020 & 0.1830 \\
\hline & AVG & 0.072 & 0.05 & 0.022 & 0.61 & 0.20 & 0.0081 & 0.0098 & 0.0020 & 0.0474 \\
\hline & STDEV & 0.014 & 0.00 & 0.014 & 0.00 & 0.00 & 0.0013 & 0.0006 & 0.0000 & 0.0391 \\
\hline \multirow[t]{4}{*}{ Khatua et al. (2012) } & Min & 0.136 & 0.12 & 0.016 & 0.22 & 0.06 & 0.0100 & 0.0100 & 0.0019 & 0.0087 \\
\hline & $\operatorname{Max}$ & 0.223 & 0.12 & 0.103 & 0.22 & 0.06 & 0.0100 & 0.0100 & 0.0019 & 0.0391 \\
\hline & AVG & 0.174 & 0.12 & 0.054 & 0.22 & 0.06 & 0.0100 & 0.0100 & 0.0019 & 0.0212 \\
\hline & STDEV & 0.031 & 0.00 & 0.031 & 0.00 & 0.00 & 0.0000 & 0.0000 & 0.0000 & 0.0111 \\
\hline \multirow[t]{4}{*}{ Ikeda and McEwan (2009) } & Min & 0.207 & 0.20 & 0.007 & 0.81 & 0.28 & 0.0100 & 0.0100 & 0.0001 & 0.0260 \\
\hline & $\operatorname{Max}$ & 0.278 & 0.20 & 0.078 & 0.81 & 0.28 & 0.0100 & 0.0100 & 0.0003 & 0.0730 \\
\hline & AVG & 0.242 & 0.20 & 0.042 & 0.81 & 0.28 & 0.0100 & 0.0100 & 0.0002 & 0.0486 \\
\hline & STDEV & 0.018 & 0.00 & 0.018 & 0.00 & 0.00 & 0.0000 & 0.0000 & 0.0001 & 0.0133 \\
\hline \multirow[t]{4}{*}{ Mohanty and Khatua (2014) } & Min & 0.071 & 0.07 & 0.006 & 1.98 & 0.17 & 0.0100 & 0.0100 & 0.0011 & 0.0130 \\
\hline & Max & 0.115 & 0.07 & 0.050 & 1.98 & 0.17 & 0.0100 & 0.0100 & 0.0011 & 0.1062 \\
\hline & AVG & 0.091 & 0.07 & 0.026 & 1.98 & 0.17 & 0.0100 & 0.0100 & 0.0011 & 0.0467 \\
\hline & STDEV & 0.016 & 0.00 & 0.016 & 0.00 & 0.00 & 0.0000 & 0.0000 & 0.0000 & 0.0326 \\
\hline
\end{tabular}



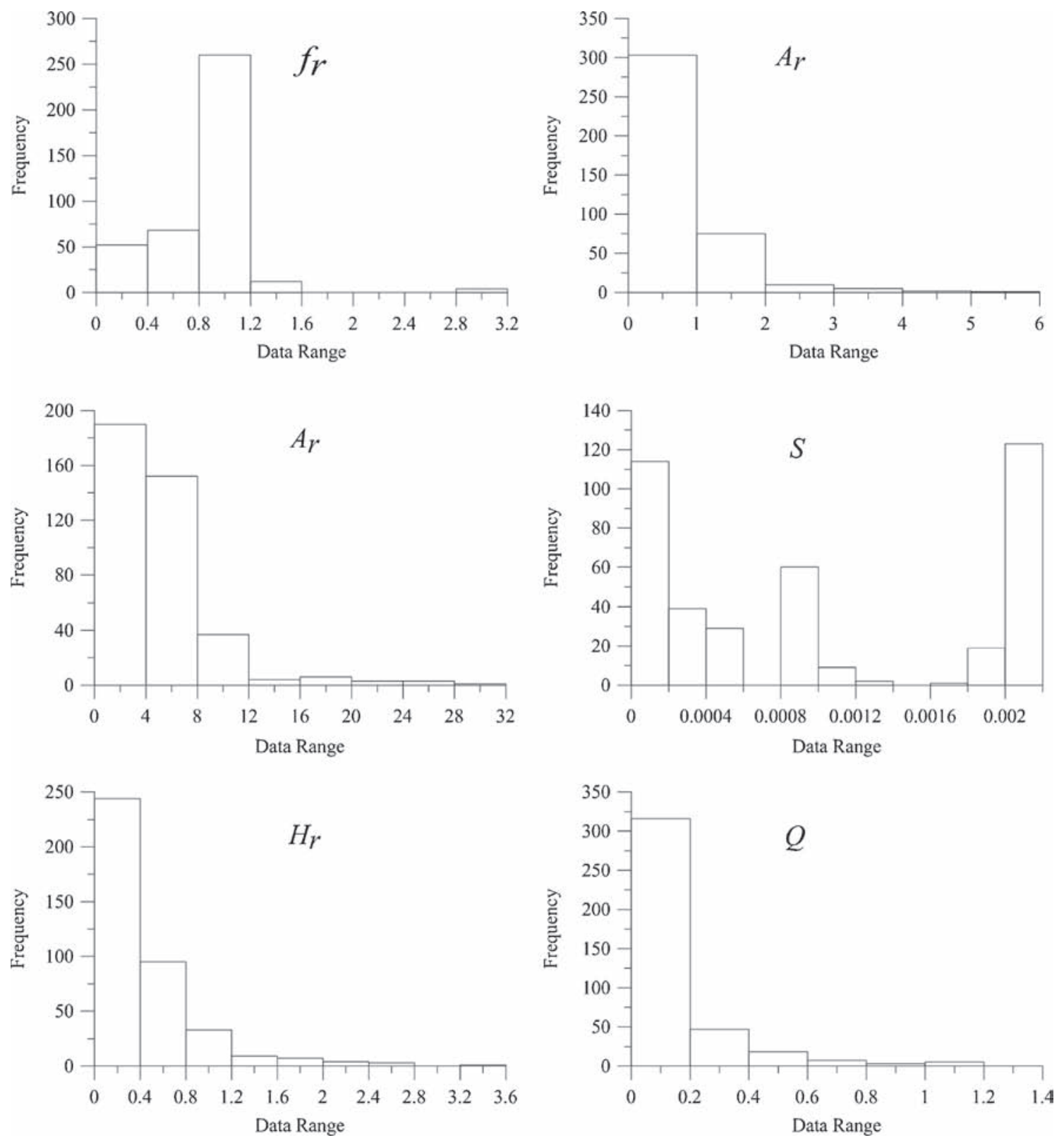

Figure 2. The histogram of collected data involved discharge of flow in compound open channel.

\subsection{Analytical approaches}

\subsubsection{Single channel method (SCM)}

The single channel method (SCM) assumes the cross-section of a COC as en-bloc. The central point in SCM is computing equivalent roughness for $\mathrm{COC}$ by common methods such as Horton and Einstein formula (equation 3a) and in the following, discharge is calculated by equation (3b).

$$
\begin{gathered}
n_{e}=\frac{\left[\sum_{i=1}^{N}\left(P_{i} n_{i}^{\frac{3}{2}}\right)\right]^{\frac{2}{3}}}{P^{\frac{2}{3}}}, \\
Q=\frac{1}{n_{e}} A R^{\frac{2}{3}} S^{\frac{1}{2}} .
\end{gathered}
$$

\subsubsection{Divided channel method (DCM)}

The divided channel method (DCM) divides the cross section of flow into subareas as main channel and floodplains. DCM assumes uniform velocity in subsections and general discharge is achieved by summation of discharge through subarea. Discharge in the subarea is computed using equation (4). As given in this equation, Manning equation is utilised for evaluating discharge and subscript $t$ is related to the subarea. The segregated border between subsections (main channel and floodplains), as shown in figure 3, could be assumed as vertical, diagonal or horizontal. Modifications have been made on DCM and in this regard, we have DCM with horizontal segregated border, which 
are included in the calculation of wetted perimeter $\left(\operatorname{DCM}_{(h-i)}\right)$ DCM with vertical separated lines, which are included in the calculation of wetted perimeter $\left(\mathrm{DCM}_{v-i}\right)$, and $\mathrm{DCM}$ with bisectional division lines, which are included in the calculation of wetted perimeter $\left(\mathrm{DCM}_{b-i}\right)$ (Atabay and Knight 2006). A number of commercial packages, such as HEC-RAS, Mike 11 and ISIS, have been developed based on DCM.

$$
Q_{t}=\left(\sum_{i=1}^{N} \frac{A_{i} R_{i}^{\frac{2}{3}}}{n_{i}}\right) S_{0}^{\frac{1}{2}} .
$$

\subsubsection{Coherence method ( $\mathrm{COH})$}

Coherence method $(\mathrm{COH})$ is a $1 \mathrm{D}$ approach recommended for rectification of transport capacity parameter in a $\mathrm{COC}$. $\mathrm{COH}$ is based on the momentum and mass transferring between main channel and floodplains. To this purpose, Ackers (1993) suggested a parameter called coherence factor. As given in equation (5), $\mathrm{COH}$ factor is defined as a ratio of the transport capacity parameter of $\mathrm{SCM}$ to DCM. If the $\mathrm{COH}$ parameter is close to 1 , the COC has a hydraulic behaviour similar to a normal channel.

$$
\begin{gathered}
C O H=\frac{\left(1+A_{r}\right)^{\frac{3}{2}} / \sqrt{\left(1+P_{r}^{\frac{4}{3}} n_{r}^{2} / A_{r}^{\frac{1}{3}}\right)}}{1+A_{r}^{\frac{5}{3}} /\left(n_{r} P_{r}^{\frac{2}{3}}\right)} \\
A_{r}=\frac{N_{f p} A_{f p}}{A_{m c}}, P_{r}=\frac{N_{f p} P_{f p}}{P_{m c}}, n_{r}=\frac{n_{f p}}{n_{m c}} .
\end{gathered}
$$

In the above equations, $N_{f p}$ denotes the number of floodplains, $A$ denotes the area of cross-section of flow, $P$ denotes the wet perimeter, and $n_{m c}$ and $n_{f p}$ denote the roughness of the main channel and the floodplains, respectively. The $\mathrm{COH}$ factor can get a value between 0 and 1 . Whenever $\mathrm{COH}$ attains a value of 1 , the COC shows a behaviour similar to a normal channel. Ackers (1993) also proposed a coefficient called the discharge adjustment factor (DISADF) to edit discharge capacity. Discharge is corrected using the values derived from figure 4 and equation (6).

$$
\text { Region 1: } \quad Q_{C O H}=Q_{D C M}-\text { DISDEF, }
$$

Regions 2, 3, 4: $\quad Q_{C O H}=\operatorname{DISADF} * Q_{D C M}$.

\subsubsection{Multivariate adaptive regression splines (MARS)}

MARS, proposed by Friedman (1991), is a pliable method to map the relationship between the independent and dependent variables in a desired system. MARS method is used to recognize the hidden patterns within dataset in complex systems. Pattern recognition is defined by proposing a number of coefficients and basic functions. The main advantages of MARS include high ability for mapping input parameters and desired outputs, developing simple but robust model and being rational in terms of computational cost. MARS technique is based on simple basic functions defined as given below:

$$
|x-t|_{+}=\max (0, x-t)= \begin{cases}x-t & x>t \\ 0 & x \leq t\end{cases}
$$

and

$$
|t-x|_{+}=\max (0, t-x)= \begin{cases}t-x & x<t \\ 0 & x \geq t\end{cases}
$$

where $t$ denotes the knot. Basic functions are sometimes also called mirrored pair-functions.

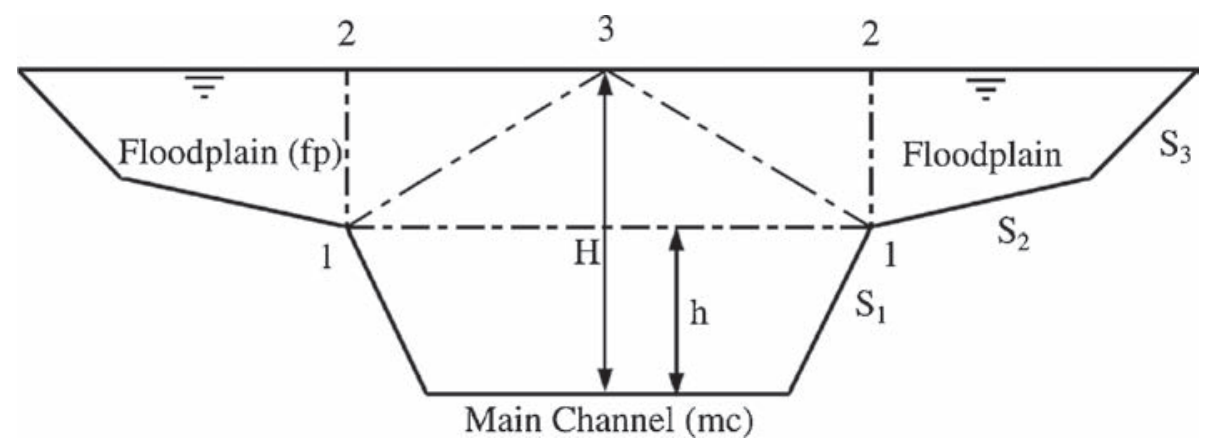

Figure 3. Types of separating the boundary between main channel and floodplains. (a-b) vertical, (a-c) diagonal, (a-a) horizontal. 
These functions are defined for each input variable such as $X_{j}$. Sets of basic functions are defined as

$$
\begin{aligned}
C= & \left\{\left(x_{j}-t\right)_{+},\left(t-x_{j}\right)_{+}\right\} ;\left\{x_{1 j}, x_{2 j}, \ldots, x_{n j}\right\}, \\
& j=1, \ldots, p .
\end{aligned}
$$

The general form of the function derived from MARS model is written as an adaptive function as follows.

$$
y=\beta_{0}+\sum_{i=1}^{M} \beta_{i} B F_{i}(X),
$$

where $\beta_{0}$ is constant, $B F_{i}(X)$ is known as basic function and $\beta_{i}$ is coefficient of basic functions. The constant and coefficient of derived function in MARS model are justified using least square error technique. $M$ is the number of basic functions derived from final stage of model development. Developing MARS model consists of two stages. The first is the forward stage where at this stage the number of basic functions is increased to decrease the difference between the results of model and observed data. In the next step of model development to avoid over-parameterisation and over-fitting, pruning some basic functions is considered. At this stage, regarding cross-validation (GCV) criteria as given below, basic functions are pruned.

$$
G C V=\frac{S S E}{n\left(1-\left(\frac{C(B)}{n}\right)\right)^{2}}
$$

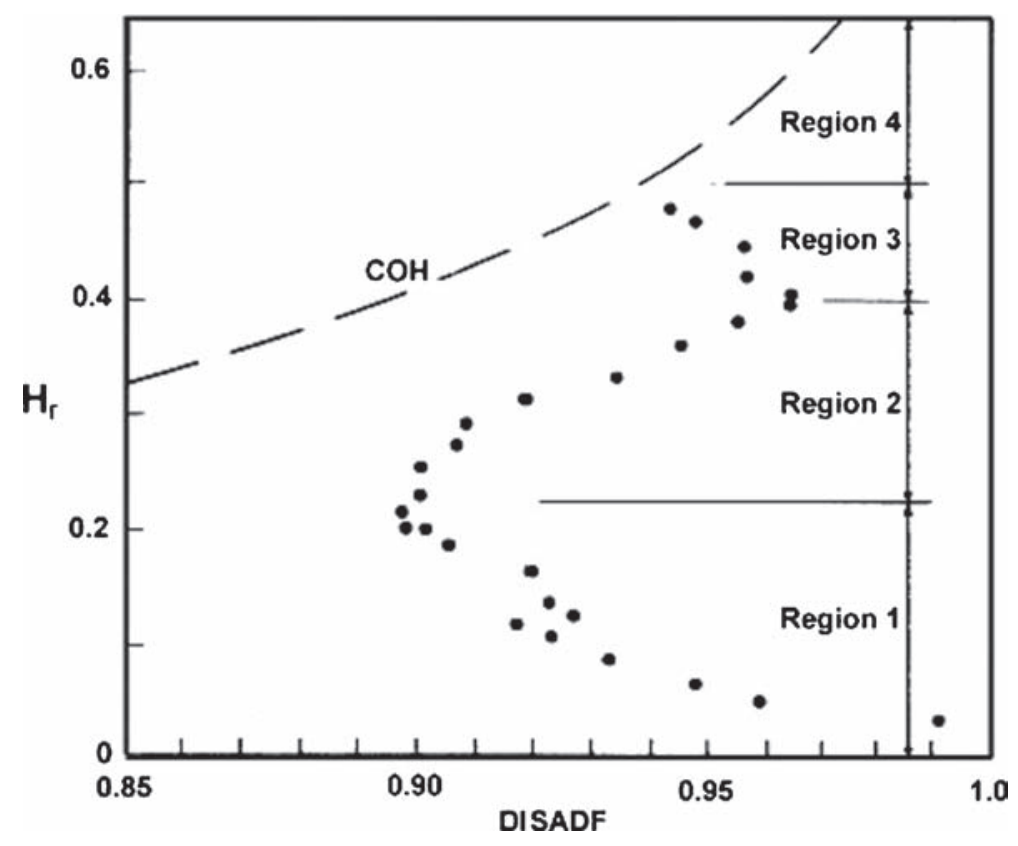

Figure 4. Diagram of adjustment parameter of flow discharge vs. relative depth.

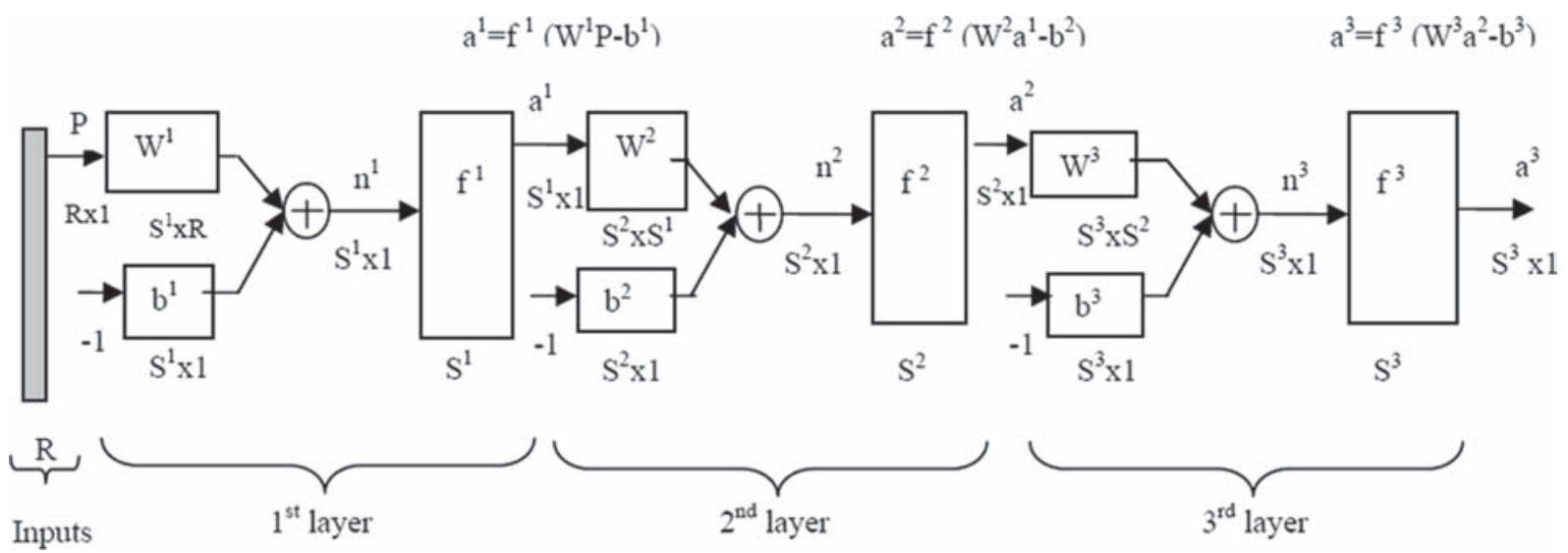

Figure 5. Sketch of three-layer ANN architecture. 
and

$$
C(B)=(B+1)+d B
$$

where $S S E_{l}$ is the sum of square of residuals, $n$ denotes the number of records and $C(B)$ defines a difficulty criteria, which increases by the number of basic functions. For more information refer Azamathulla et al. (2016) and Parsaie et al. (2016a).

\subsection{Artificial neural networks (ANNs)}

ANN is a popular computing technique that was developed to simulate complex problems that are
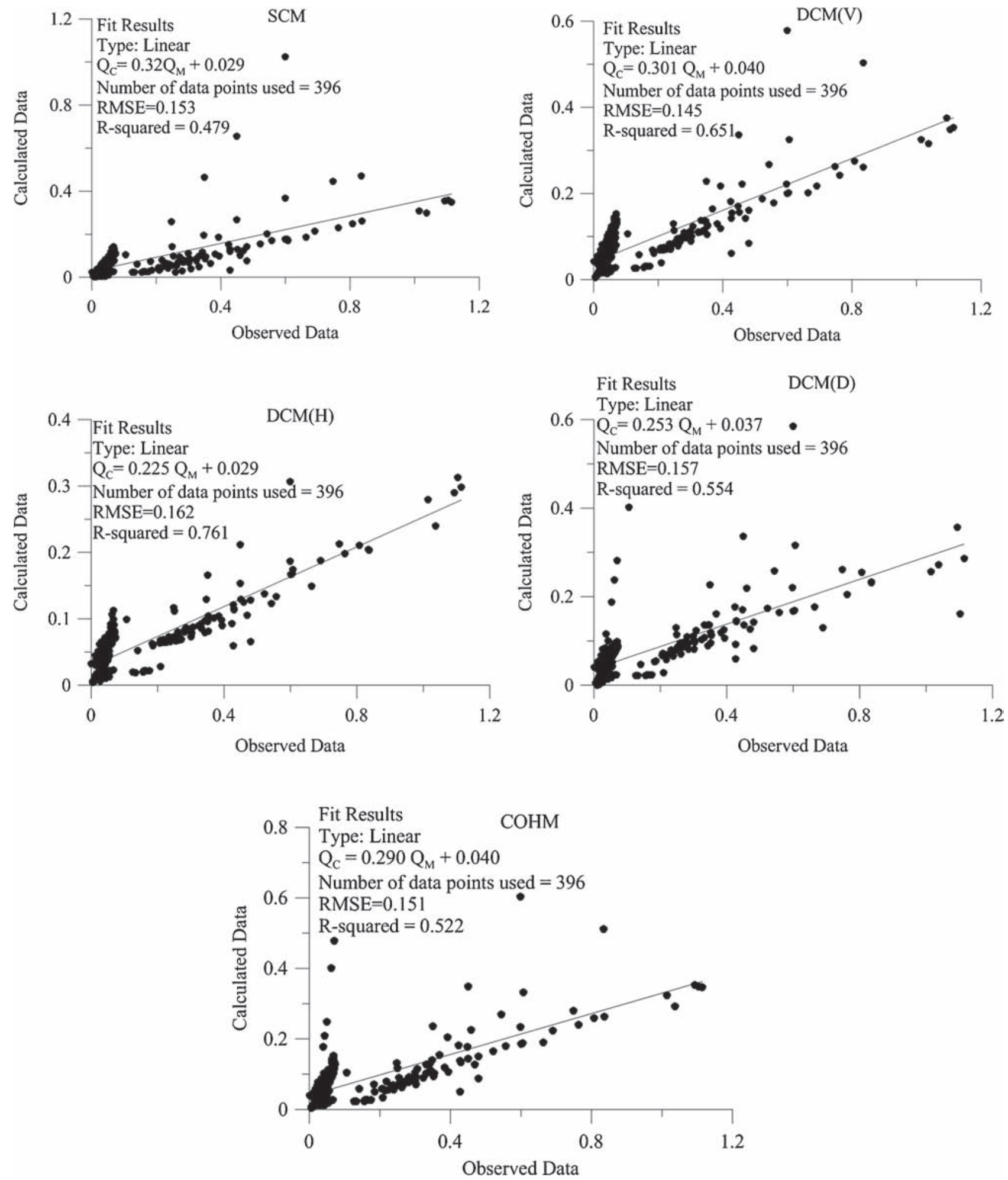

Figure 6. Correlation between results of analytical approaches vs. measured discharge. 
based on inputs and outputs. MLP networks are well-known types of ANN that have widely been used for modelling and predicting the engineering phenomena. Preparation of MLP models include a number of steps such as designing the structure of network, choosing of transfer functions, adjusting the values of weights and bias. Different types of transfer functions are proposed for governing the neurons. MLP model could take one or more hidden layers. Figure 5 shows a MLP model including three hidden layers. As shown in figure 5, each input is multiplied with a weight $\left(w_{i}\right)$, following which their summation is added to a bias $\left(b_{i}\right)$ and then passed through the transfer function. After definition of model structure, training algorithm should be considered. Training here implies adjusting the values of weights and biases. This operation is carried out using progressive approaches such as the Levenberg-Marquardt technique. The goal of model training is minimising the errors by comparing the predicted outputs with observed data.

\section{Results and discussion}

\subsection{Results of analytical approach}

The analytical approaches MLP and MARS models were assessed using collected datasets, the histograms of which are shown in figure 2. Accuracy of analytical approaches, MLP and MARS models were evaluated by calculation of error indices such as coefficient of determination $\left(R^{2}\right)$ and root mean square error (RMSE). It must be noted that these indices offer an average value for error and do not present any detail about distribution of error through dataset. Therefore, in addition to computing error indices, it is desirable to plot the results of these methods against the measured data. Figure 6 shows the results of analytical approaches compared to measured data. The values of the error indices for the results of analytical methods are also shown in figure 6 . Considering figure $6, \mathrm{DCM}_{h-i}$, $\mathrm{DCM}_{h-e}$ and $\mathrm{DCM}_{v-i}$ are more accurate compared to other analytical approaches. The suitable accuracy of these methods can be ascribed to the fact that the cross-section of the COC were divided into a main channel and floodplains and also to the fact that the concept of mass and momentum transferring between subsections of COC were considered. Figure 6 shows the performance of each analytical approach versus measured data. Considering figure 6 , it seems that the best analytical approach is $\mathrm{DCM}_{\mathrm{h}-\mathrm{i}}$, since in addition to having good values for the error indices, it also has a suitable performance for predicting discharge in high value of discharge.

\subsection{Results of MLP model}

The first step in the development of neural networks is data preparation. This means that part of the dataset should be assigned for model development (calibration stage) and another part should be assigned for model validation (testing stage). The portion of each stage from the collected dataset is defined via a trial-and-error process. However, the experience of the designer and recommendation of investigators who have conducted similar work is useful. Eighty percent of the dataset was considered for calibration, and the remaining $20 \%$ for validation. Designing the architecture of ANN

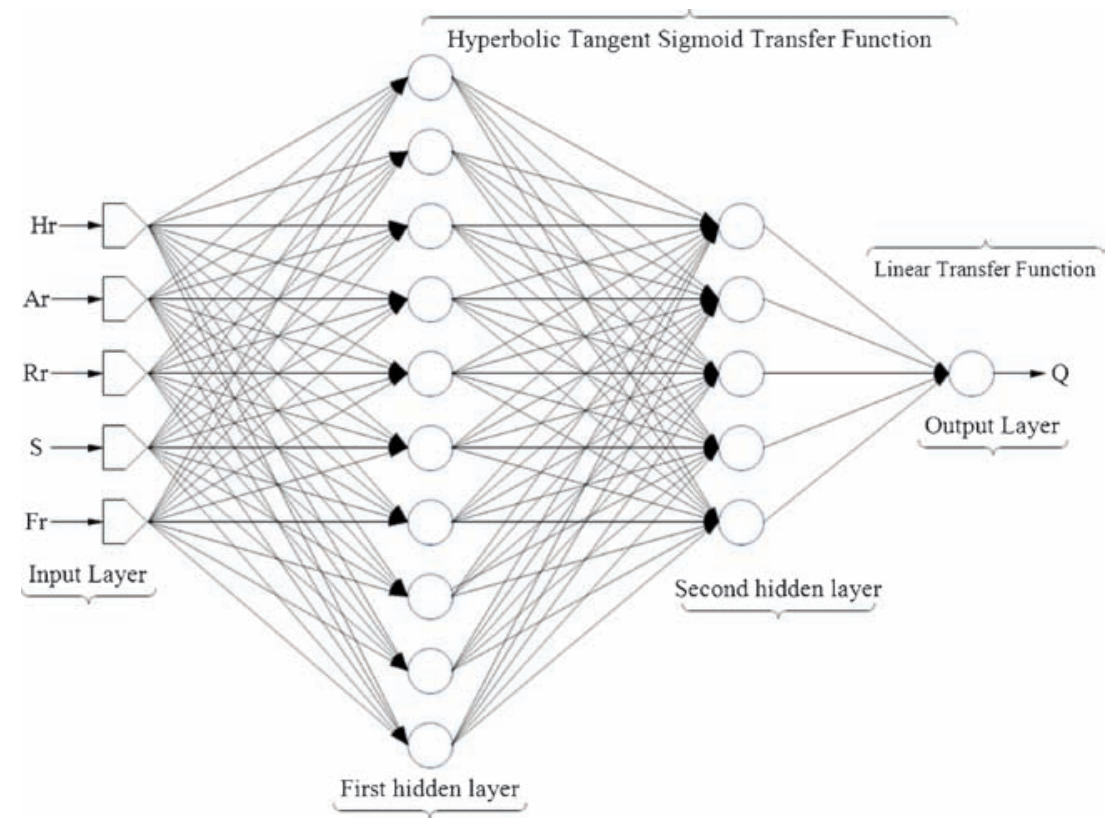

Figure 7. Architecture of developed MLP model. 

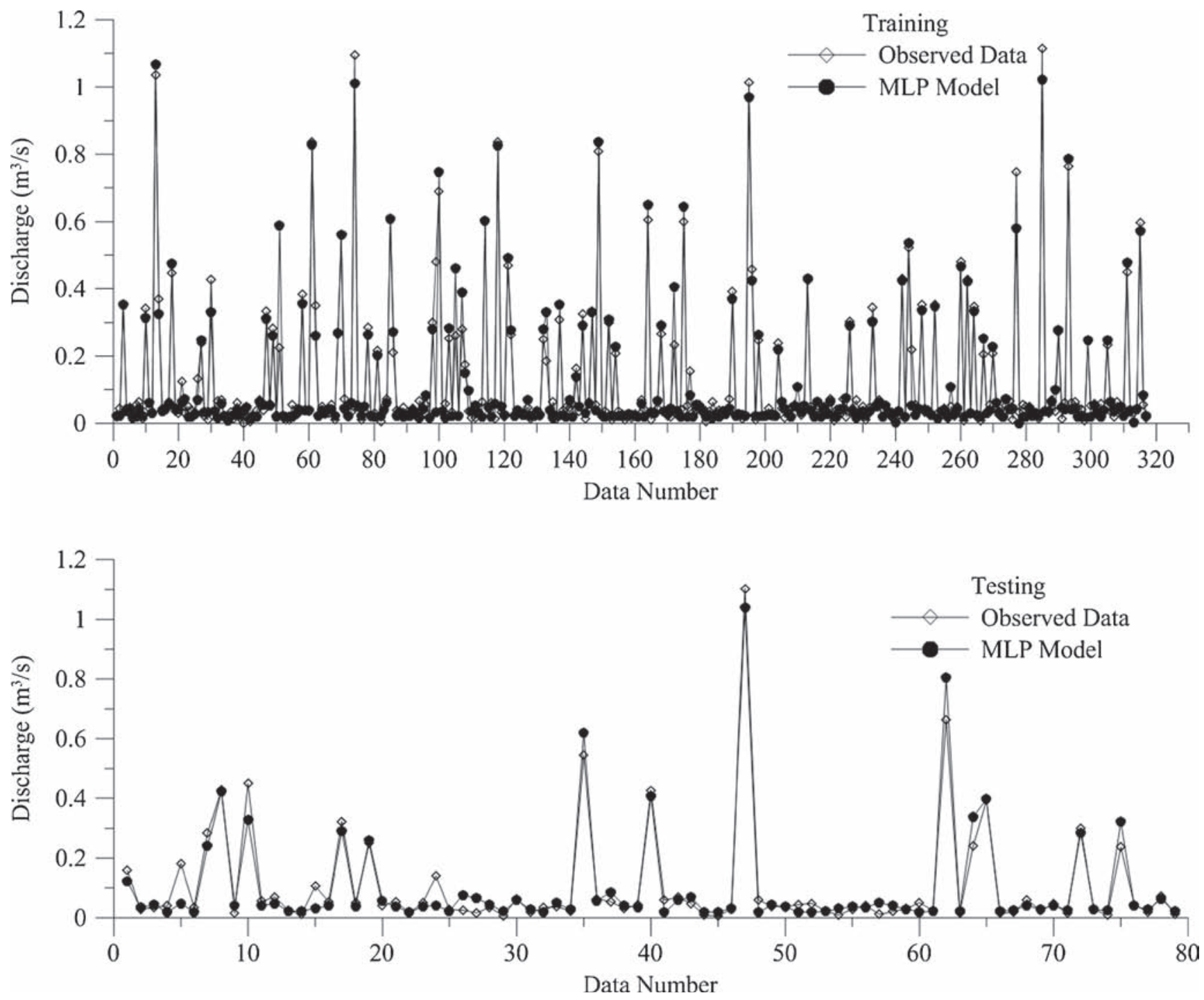

Figure 8. Performance of MLP model during training stage.
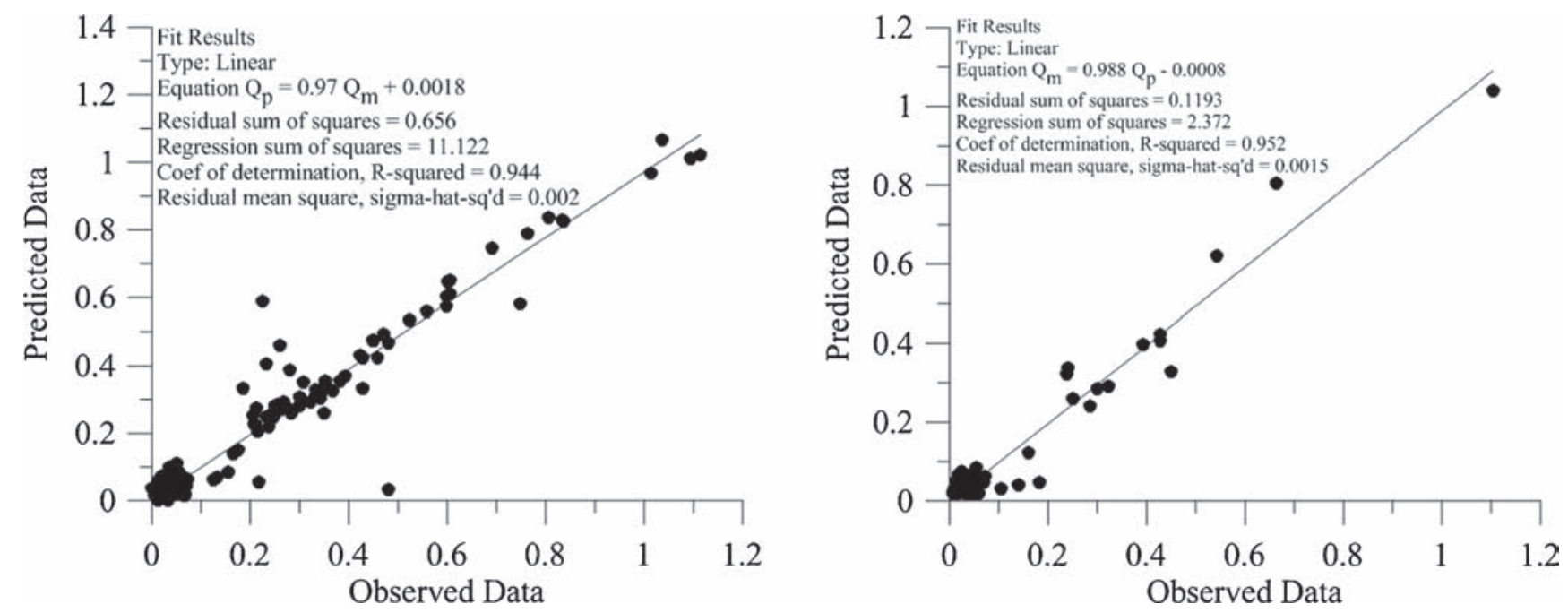

Figure 9. Performance of MLP model during testing stage. 
model is also a trial-and-error process, where recommendations of others who utilised other types of soft computing in this regard could be useful. In this research, the recommendation of Sahu et al. (2011) was used. Designing the structure of MLP model includes using a number of hidden layer(s), a number of neurons in each layer, assigning suitable transfer function for neurons and training algorithm. Since, the flow in a $\mathrm{COC}$ is a fully complex hydraulic phenomena, it was expected that the MLP model was not of a small size. To achieve an optimum structure for the MLP model, the size of model is increased step by step. Different transfer functions including logsig (Log-Sigmoid Transfer Function), tansig (Hyperbolic Tangent Sigmoid Transfer Function), purelin (Linear Transfer Function) were tested. In other words, firstly, a model with one hidden layer involved five neurons (equal to features of inputs) was considered. Then the transfer functions were tested. By choosing the proper transfer function in the next step was to improve the precision of developed MLP model, the number of neurons and hidden layer could be increased. This approach leads to achieving optimum structure and suitable performance in terms of computation cost. During the development of the MLP model, it was found that the model structure, shown in figure 7 , has a suitable performance for predicting flow discharge in COC and increasing the number of hidden layers only increases the computational cost and has no significant effect in improving the performance of model. Figure 7 shows the architecture of the developed MLP model. As can be seen from figure 7, the MLP model consists of two hidden layers that first and second hidden layers include ten and five neurons with the tansig transfer function, respectively. Levenberg-Marquardt technique was used for MLP model learning.

As seen in figure 7 and with respect to equation (2), dimensionless parameters such as $f_{r}, A_{r}, R_{r}, S$ and $H_{r}$ were considered as input parameters and $Q$ as the output parameter. The performance of MLP model during calibration (training) and validation (testing) stages are given in figures 8 and 9. In these figures, the results of the MLP model along and vs. the observed data are shown. Overall, these results of MLP show that the

Table 2. Basic functions and related coefficients of MARS model.

\begin{tabular}{|c|c|c|}
\hline Basic function & Equation & Coefficient \\
\hline$h_{1}(x)$ & $\mathrm{BF} 1=\max (0,0.00019-\mathrm{S})$ & 5504.451 \\
\hline$h_{2}(x)$ & $\mathrm{BF} 2=\max (0, \mathrm{~S}-0.0001)$ & 7196.574 \\
\hline$h_{3}(x)$ & $\mathrm{BF} 3=\max (0,0.0001-\mathrm{S})$ & -114469.959 \\
\hline$h_{4}(x)$ & $\mathrm{BF} 4=\max \left(0, f_{r}-1.261\right)$ & -0.041 \\
\hline$h_{5}(x)$ & $\mathrm{BF} 5=\max \left(0, A_{r}-0.574\right)$ & 0.197 \\
\hline$h_{6}(x)$ & $\mathrm{BF} 6=\max (0, \mathrm{~S}-0.0002) * \max \left(0, H_{r}-0.794\right)$ & 4949.876 \\
\hline$h_{7}(x)$ & $\mathrm{BF} 7=\max (0, \mathrm{~S}-0.0002) * \max \left(0,0.749-H_{r}\right)$ & -4705.815 \\
\hline$h_{8}(x)$ & $\mathrm{BF} 8=\max \left(0,1.261-f_{r}\right) * \max \left(0,0.342-A_{r}\right)$ & -7.416 \\
\hline$h_{9}(x)$ & $\mathrm{BF} 9=\mathrm{BF} 2 * \max \left(0, H_{r}-0.417\right)$ & -4681.751 \\
\hline$h_{10}(x)$ & $\mathrm{BF} 10=\mathrm{BF} 2 * \max \left(0,0.417-H_{r}\right)$ & 4427.788 \\
\hline$h_{11}(x)$ & $\mathrm{BF} 11=\max \left(0,0.857-H_{r}\right)$ & 2.007 \\
\hline$h_{12}(x)$ & $\mathrm{BF} 12=\mathrm{BF} 11 * \max (0, \mathrm{~S}-0.002)$ & -10818.362 \\
\hline$h_{13}(x)$ & $\mathrm{BF} 13=\mathrm{BF} 11 * \max (0,0.002-\mathrm{S})$ & 5594.686 \\
\hline$h_{14}(x)$ & $\mathrm{BF} 14=\max (0,0.001-\mathrm{S})$ & -183.352 \\
\hline$h_{15}(x)$ & $\mathrm{BF} 15=\mathrm{BF} 11 * \max (0,0.002-\mathrm{S})$ & -7865.379 \\
\hline$h_{16}(x)$ & $\mathrm{BF} 16=\max (0, \mathrm{~S}-0.0011) * \max \left(0, A_{r}-0.456\right)$ & -627.501 \\
\hline$h_{17}(x)$ & $\mathrm{BF} 17=\max (0, \mathrm{~S}-0.0011) * \max \left(0,0.456-A_{r}\right)$ & 5687.774 \\
\hline$h_{18}(x)$ & $\mathrm{BF} 18=\mathrm{BF} 14 * \max \left(0,0.425-A_{r}\right)$ & 1309.383 \\
\hline$h_{19}(x)$ & $\mathrm{BF} 19=\mathrm{BF} 14 * \max \left(0, H_{r}-0.567\right)$ & -793.312 \\
\hline$h_{20}(x)$ & $\mathrm{BF} 20=\mathrm{BF} 14 * \max \left(0,0.567-H_{r}\right)$ & 2103.869 \\
\hline$h_{21}(x)$ & $\mathrm{BF} 21=\max (0,0.002-\mathrm{S})$ & 6305.094 \\
\hline$h_{22}(x)$ & $\mathrm{BF} 22=\max (0, \mathrm{~S}-0.0019) * \max \left(0, A_{r}-0.456\right)$ & 5068.522 \\
\hline$h_{23}(x)$ & $\mathrm{BF} 23=\max (0, \mathrm{~S}-0.002) * \max \left(0,0.456-A_{r}\right)$ & -38488.855 \\
\hline$h_{24}(x)$ & $\mathrm{BF} 24=\max \left(0,1.261-f_{r}\right) * \max \left(0,2.087-R_{r}\right)$ & 0.715 \\
\hline$h_{25}(x)$ & $\mathrm{BF} 25=\max \left(0, A_{r}-0.311\right)$ & -0.200 \\
\hline$h_{26}(x)$ & $\mathrm{BF} 26=\max \left(0,0.311-A_{r}\right)$ & 2.375 \\
\hline
\end{tabular}


performance of MLP is appropriate for predicting flow discharge in a COC.

\section{Results of MARS model}

Developing a MARS model similar to MLP model is based on the dataset. To this end, the collected dataset, which was used for preparation of MLP model (training: 80\% and testing: 20\%), was also used for developing MARS technique. During MARS model development, in the first step, thirty basic functions were considered and in the second (pruning) step, five basic functions were pruned. In the end, the optimal MARS model was derived with 26 basic functions. The general form of obtained MARS model is given in equation (11).
The extended form of MARS model is given in table 2 .

$$
Q=-10.436+\sum_{M=1}^{26} \beta_{m} h_{m}(x) .
$$

Equation (11) can be used for estimating discharge capacity in a COC. As seen in table $2, S, H_{r}$ and $A_{r}$ have appeared in almost all basic functions. It means that these three parameters are more affective compared to others. This obtained result of the MARS model upholds the results of the study that was conducted by Sahu et al. (2011). They declared that the sensitivity analysis of the developed ANN model indicated that $H_{r}$ and $A_{r}$ were the most effective parameters for predicting the discharge of flow in COC. Moreover, the performances
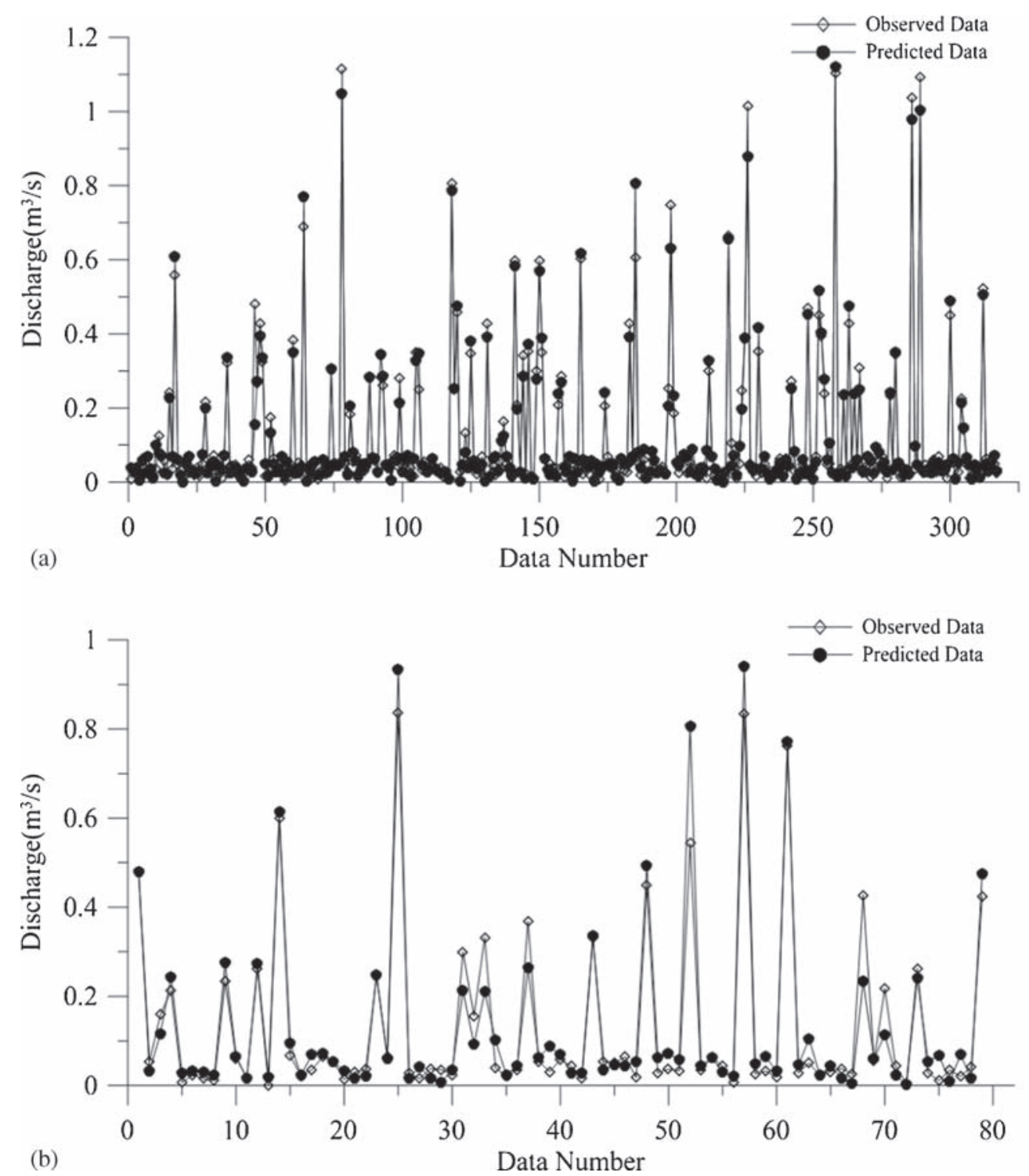

Figure 10. Results of MARS model along observed data during training (a) and testing (b) stages. 

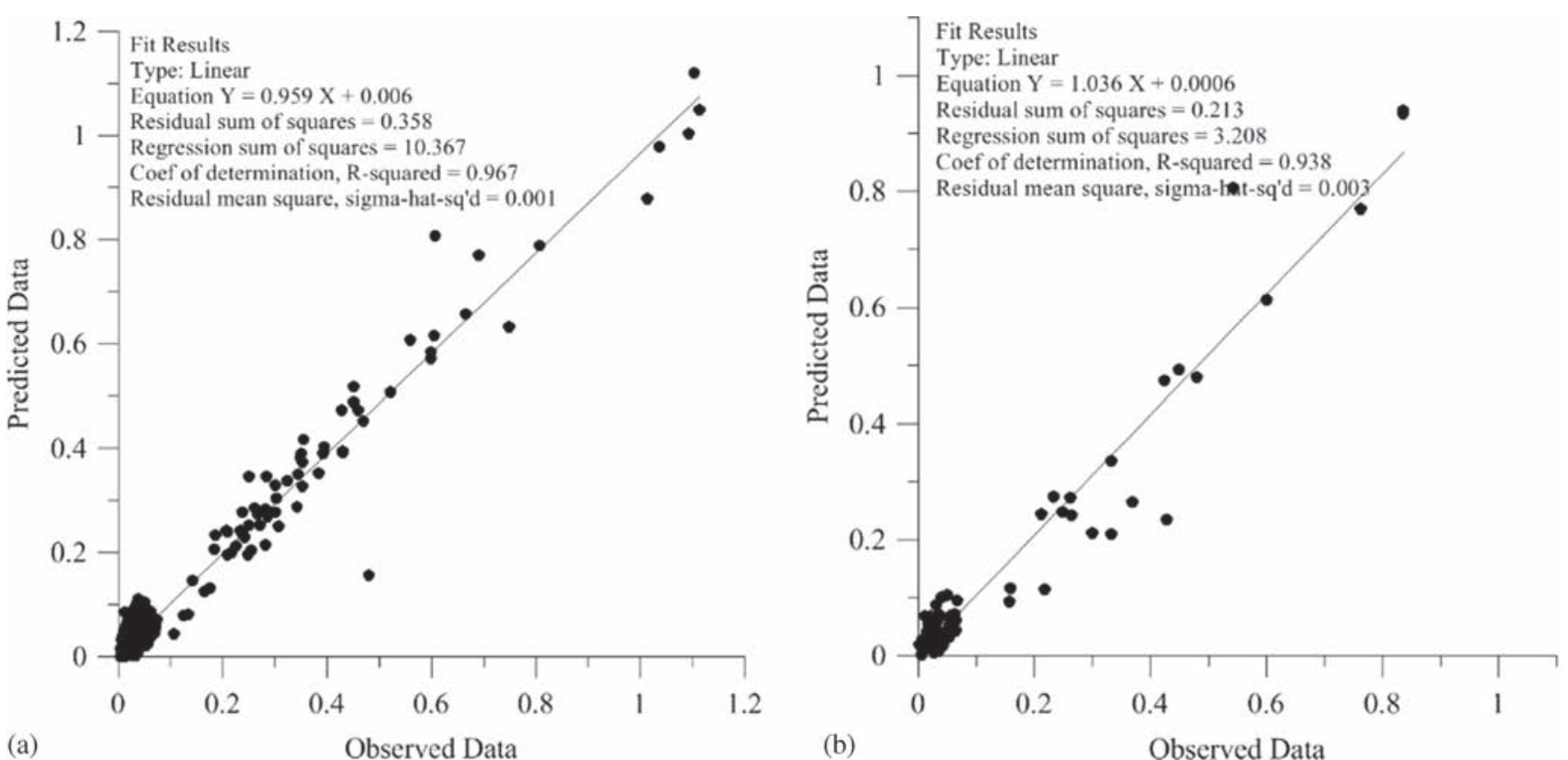

Figure 11. Results of MARS model vs. observed data in training (a) and testing (b) stages.

of the MARS model during preparation stages (training and testing stages) are given in figures 10 and 11 . Figures 10 and 11 show the plotted measured data and results of MARS model. Additionally, the results of error indices calculation are also indicated in these figures. From figures 10 and 11, it can be that the performance of MARS model for prediction of flow discharge is very appropriate.

\subsection{Comparison of the performances}

A comparison of the results of MLP, MARS and $\mathrm{DCM}_{\mathrm{H}}$ shows that in the preparation stages, including training and testing stages, MARS model is a bit more accurate than MLP. This assessment was obtained considering the calculation of standard error indices such as coefficient of determination and mean square of errors. Figure 12 shows the outcome of MARS, MLP and $\mathrm{DCM}_{\mathrm{H}}$ for testing dataset. As shown in this figure, the best performance of models is related to MARS and MLP. Although the $\mathrm{DCM}_{\mathrm{H}}$ has performance in all datasets, but for testing dataset, its precision is reduced.

Standard error indices provide an average value for errors, whereas they do not present detailed information on distribution of errors. Therefore, it is necessary to assess the performance of the model and apply another evaluation criterion. In this paper, the developed discrepancy ratio (DDR) introduced by Noori et al. (2010) was applied. This index has also been used in several studies namely

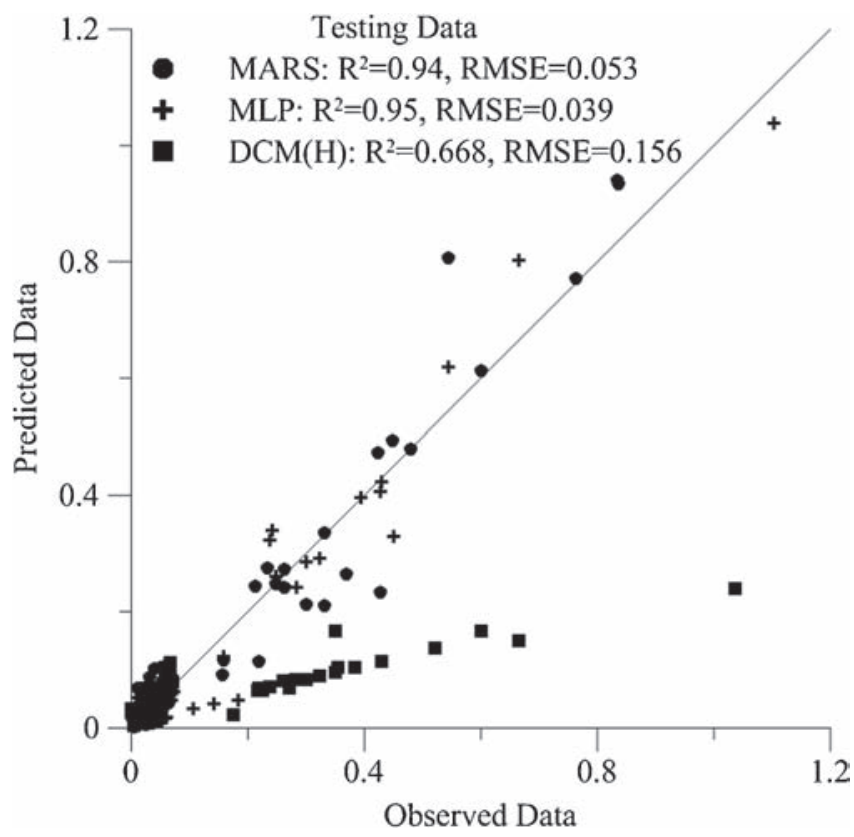

Figure 12. Performance of MARS, MLP and DCM (H) for testing data.

Noori and Hooshyaripor (2014) as well as Dehghani et al. (2014). DDR is calculated as follows:

$$
\mathrm{DDR}=\left(\frac{\text { Predicted value }}{\text { Observed value }}\right)-1
$$

Results of DDR calculation for both models in training (a) and testing (b) stages are given in figures 13 and 14. Comparing the performances of 


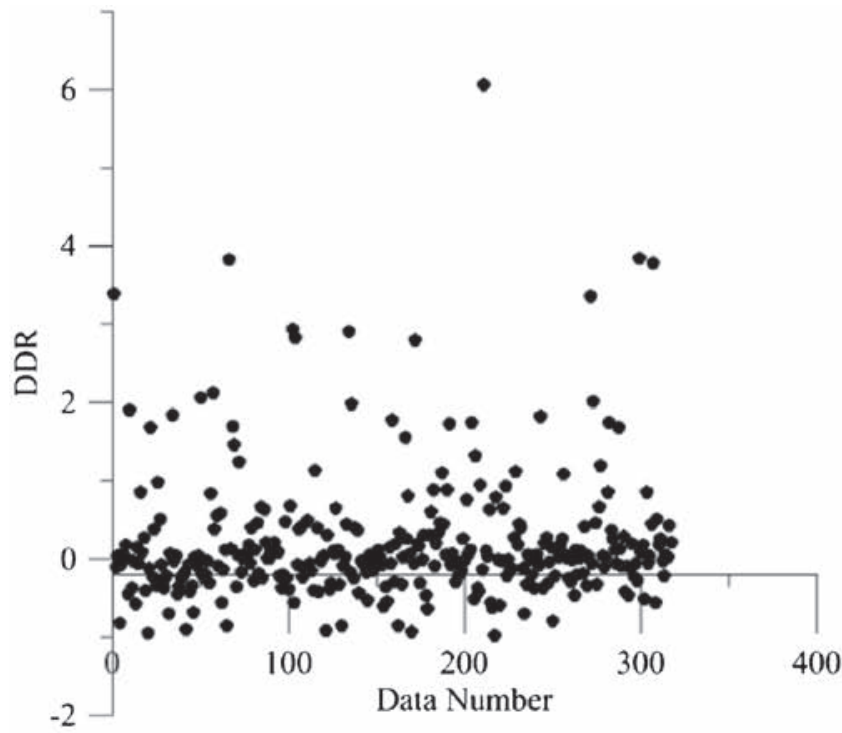

(a)

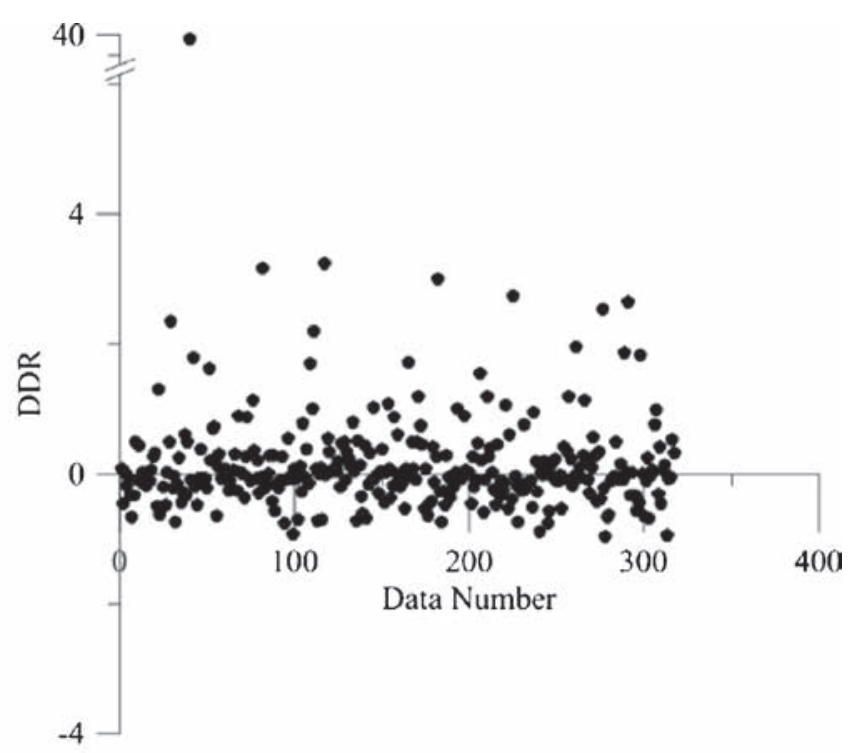

(b)

Figure 13. DDR values for MARS (a) MLP and (b) models in training stages.

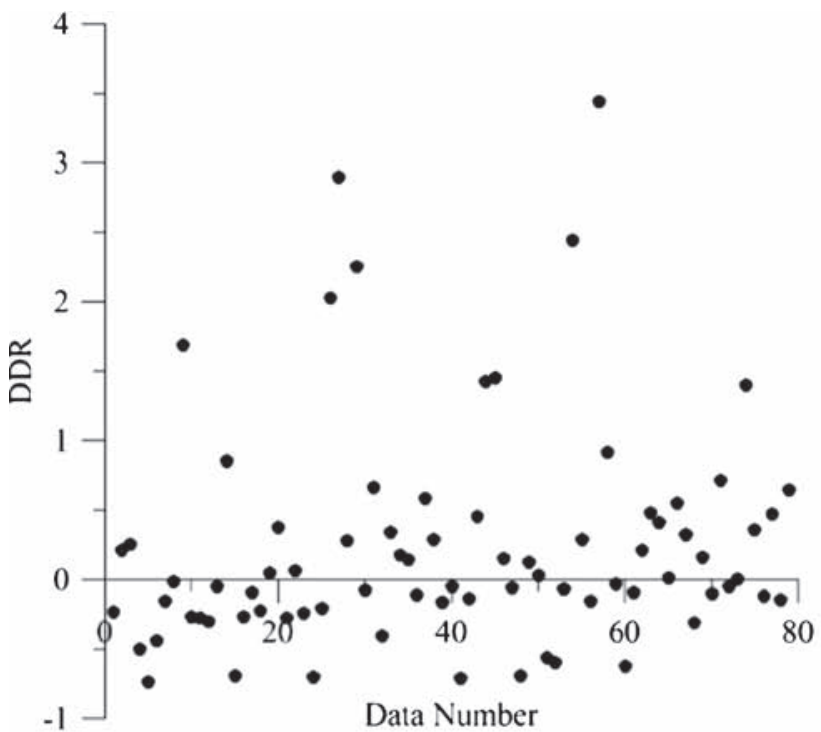

(a)

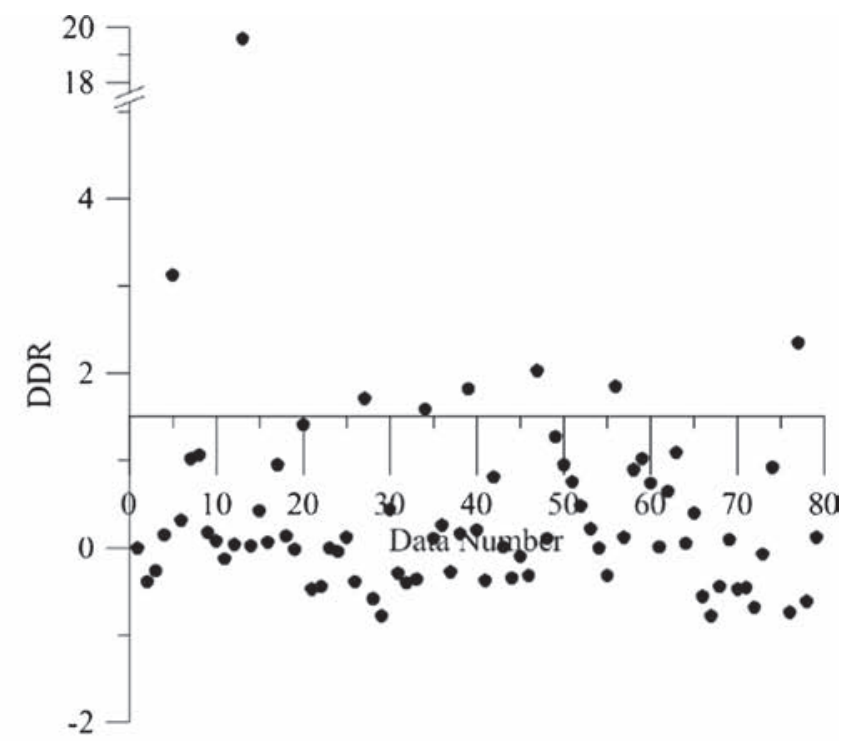

(b)

Figure 14. DDR values for MARS (a) MLP and (b) models in testing stages.

MARS and MLP in terms of DDR index shows that MARS model is more accurate.

\section{Conclusion}

Predicting flow discharge in rivers is important when developing hydro system projects. COC is a novel concept and an accurate approach proposed for calculating flow discharge in rivers. Several proposed analytical approaches are based on this concept. Recently, by advances in soft computing techniques in most areas, especially in water engineering studies, these models have been applied for predicting flow discharge in COCs. Today, new soft computing models namely MARS have been proposed for modelling complex systems, which are based on inputs and output dataset. The main advantage of MARS model is its ability to yield clear information about internal processes, which is carried out in the model development process. Results of this study showed that MARS model is very appropriate for predicting flow discharge in a COC. Another advantage of MARS model is related to programing its results for other purposes.

\section{Acknowledgement}

We are grateful to Dr Hojjatallah Yonesi, Assistant Professor at Lorestan University, Khorramabad, 
Iran, who introduced us to the advanced concept of compound open channel hydraulics.

\section{References}

Ackers P 1993 Flow formulae for straight two-stage channels; J. Hydraul. Res. 31 509-531.

Atabay S and Knight D W 2006 1-D modelling of conveyance, boundary shear and sediment transport in overbank flow; J. Hydraul. Res. 44 739-754.

Azamathulla H M and Zahiri A 2012 Flow discharge prediction in compound channels using linear genetic programming; J. Hydrol. 454-455 203-207.

Azamathulla H M, Haghiabi A H and Parsaie A 2016 Prediction of side weir discharge coefficient by support vector machine technique; Water Sci. Technol.: Water Suppl. 16 1002-1016.

Chatila J G and Townsend R D 1996 Discharge estimation methods for steady compound channel flows; Canadian Water Resour. J./Revue canadienne des ressources hydriques 21 131-137.

Chaudhry M H 2007 Open-Channel Flow; Springer US.

Chow V 2009 Open-Channel Hydraulics; Blackburn Press.

Chow V, Maidment D and Mays L 2013 Applied Hydrology; 2nd edn; McGraw-Hill Companies, Inc.

Dehdar-behbahani S and Parsaie A 2016 Numerical modeling of flow pattern in dam spillway's guide wall. Case study: Balaroud dam, Iran; Alexandria Eng. J. 55 467-473.

Dehghani M, Saghafian B, Nasiri Saleh F, Farokhnia A and Noori R 2014 Uncertainty analysis of streamflow drought forecast using artificial neural networks and Monte-Carlo simulation; Int. J. Climatol. 34 1169-1180.

Fernandes J N, Leal J B and Cardoso A H 2015 Assessment of stage-discharge predictors for compound open-channels; Flow Meas. Instrum. 45 62-67.

Friedman J H 1991 Multivariate adaptive regression splines; The Annals of Statistics 19 1-67.

Haghiabi A H 2016a Prediction of longitudinal dispersion coefficient using multivariate adaptive regression splines; J. Earth Syst. Sci. 125 985-995.

Haghiabi A H 2016b Prediction of river pipeline scour depth using multivariate adaptive regression splines; J. Pipeline Syst. Eng. Pract. 8(1) 04016015, doi: 10.1061/(asce)ps.1949-1204.0000248.

Ikeda S and McEwan I K 2009 Flow and sediment transport in compound channels: The experience of Japanese and UK research; Taylor \& Francis.

Khatua K, Patra K and Mohanty P 2012 Stage-discharge prediction for straight and smooth compound channels with wide floodplains; J. Hydraul. Eng. 138 93-99.

Knight D W, Demetriou J D and Hamed M E 1984 Stagedischarge relationships for compound channels; In: Channels and channel control structure (ed.) Smith K V H; Springer Berlin Heidelberg, pp. 445-459.

Lenton R and Muller M 2012 Integrated water resources management in practice: Better water management for development; Taylor \& Francis.

Mohanty P K and Khatua K K 2014 Estimation of discharge and its distribution in compound channels; J. Hydrodyn. B 26 144-154.

Myers W R C 1987 Velocity and discharge in compound channels; J. Hydraul. Eng. 113 753-766.

Najafzadeh M 2016 Neurofuzzy-based GMDH-PSO to predict maximum scour depth at equilibrium at culvert outlets; J. Pipeline Syst. Eng. Pract. 706015001.

Najafzadeh M and Lim S Y 2015 Application of improved neuro-fuzzy GMDH to predict scour depth at sluice gates; Earth Sci. Inform. 8 187-196.
Najafzadeh M and Tafarojnoruz A 2016 Evaluation of neuro-fuzzy GMDH-based particle swarm optimization to predict longitudinal dispersion coefficient in rivers; Environ. Earth Sci. 75 1-12.

Najafzadeh M and Zahiri A 2015 Neuro-fuzzy GMDHbased evolutionary algorithms to predict flow discharge in straight compound channels; J. Hydrol. Eng. 20 04015035 .

Najafzadeh M, Barani G-A and Azamathulla H M 2013 GMDH to predict scour depth around a pier in cohesive soils; Appl. Ocean Res. 40 35-41.

Najafzadeh M, Etemad-Shahidi A and Lim S Y 2016 Scour prediction in long contractions using ANFIS and SVM; Ocean Eng. 111 128-135.

Naot D, Nezu I and Nakagawa H 1993 Calculation of compound-open-channel flow; J. Hydraul. Eng. 119 1418-1426.

Noori R and Hooshyaripor F 2014 Effective prediction of scour downstream of ski-jump buckets using artificial neural networks; Water Resour. 41 8-18.

Noori R, Khakpour A, Omidvar B and Farokhnia A 2010 Comparison of ANN and principal component analysismultivariate linear regression models for predicting the river flow based on developed discrepancy ratio statistic; Expert Syst. Appl. 37 5856-5862.

Noori R, Karbassi A, Ashrafi K, Ardestani M, Mehrdadi N and Nabi Bidhendi G-R 2012 Active and online prediction of BOD5 in river systems using reduced-order support vector machine; Environ. Earth Sci. 67 141-149.

Noori R, Yeh H-D, Abbasi M, Kachoosangi F T and Moazami S 2015 Uncertainty analysis of support vector machine for online prediction of five-day biochemical oxygen demand; J. Hydrol. 527 833-843.

Noori R, Deng Z, Kiaghadi A and Kachoosangi F T 2016 How reliable are ANN, ANFIS, and SVM techniques for predicting longitudinal dispersion coefficient in natural rivers? J. Hydraul. Eng. 14204015039.

Parsaie A 2016 Analyzing the distribution of momentum and energy coefficients in compound open channel; Model. Earth Syst. Environ. 2 1-5.

Parsaie A and Haghiabi A H 2015 Computational modeling of pollution transmission in rivers; Appl. Water Sci., pp. 1-10.

Parsaie A, Haghiabi A H, Saneie M and Torabi H 2016a Prediction of energy dissipation on the stepped spillway using the multivariate adaptive regression splines; $I S H J$. Hydraul. Eng. 22 281-292.

Parsaie A, Najafian S, Omid M H and Yonesi H 2016b Stage discharge prediction in heterogeneous compound open channel roughness; ISH J. Hydraul. Eng., pp. 1-8.

Reddy H P, Chaudhry M H and Imran J 2014 Computation of gradually varied flow in compound open channel networks; Sadhana 39 1523-1545.

Sahu M 2012 Prediction of flow and its resistance in compound open channels: Turbulent flow and its assessment for compound open channel flow; Lambert Academic Publishing.

Sahu M, Khatua K K and Mahapatra S S 2011 A neural network approach for prediction of discharge in straight compound open channel flow; Flow Mea. Instrum. 22 438-446.

Samadi M, Jabbari E, Azamathulla H and Mojallal M 2015 Estimation of scour depth below free overfall spillways using multivariate adaptive regression splines and artificial neural networks; Eng. Appl. Comput. Fluid Mech. 9(1) 291-300.

Seckin G 2004 A comparison of one-dimensional methods for estimating discharge capacity of straight compound channels; Canadian J. Civil Eng. 31 619-631.

Seckin G, Mamak M, Atabay S and Omran M 2009 Discharge estimation in compound channels with fixed and mobile bed; Sadhana 34 923-945. 
Sharda V, Prasher S, Patel R, Ojasvi P and Prakash C 2008 Performance of multivariate adaptive regression splines (MARS) in predicting runoff in mid-Himalayan microwatersheds with limited data; Hydrol. Sci. J. 53 1165-1175.

Subramanya K 2009 Flow in open channels; Tata McGraw-Hill.

Tang X, Knight D W and Samuels P G 1999 Variable parameter Muskingum-Cunge method for flood routing in a compound channel; J. Hydraul. Res. 37 591-614.

Unal B, Mamak M, Seckin G and Cobaner M 2010 Comparison of an ANN approach with 1-D and 2-D methods for estimating discharge capacity of straight compound channels; Adv. Engin. Softw. 41 120-129.
Wormleaton P and Hadjipanos P 1985 Flow distribution in compound channels; J. Hydraul. Eng. 111 357-361.

Wormleaton P R and Merrett D J 1990 An improved method of calculation for steady uniform flow in prismatic main channel/flood plain sections; J. Hydraul. Res. 28 $157-174$.

Zahiri A and Azamathulla H M 2014 Comparison between linear genetic programming and M5 tree models to predict flow discharge in compound channels; Neural Comput. Appl. 24 413-420.

Zhang W and Goh A T C 2014 Multivariate adaptive regression splines and neural network models for prediction of pile drivability; Geosci. Front. 7(1) 45-52.

MS received 3 August 2016; revised 14 November 2016; accepted 15 November 2016

Corresponding editor: Subimal Ghosh 